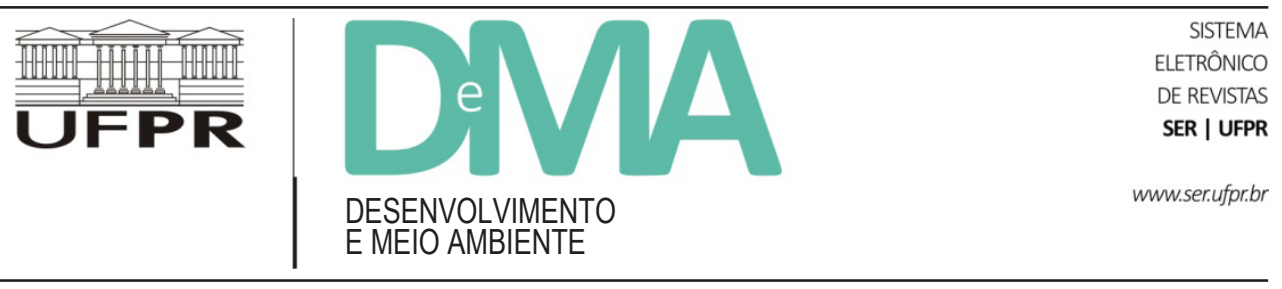

\title{
A remanufatura de equipamentos eletroeletrônicos como contribuição para o desenvolvimento sustentável: uma avaliação do caso dos refrigeradores
}

\section{The Electrical and Electronic Equipment Remanufacturing as a Contribution to Sustainable Development: An Evaluation of the Case of Refrigerators}

\author{
Laurentina Martins PAIVA ${ }^{1}$, Eduardo Gonçalves SERRA² \\ ${ }^{1}$ Mestra em Engenharia Ambiental (UFRJ). Engenheira da Marinha do Brasil. E-mail: laurentinamartins@gmail.com \\ ${ }^{2}$ Doutor em Engenharia Oceânica (UFRJ). Professor do Programa de Engenharia Ambiental da Universidade Federal do Rio de Janeiro (UFRJ). \\ E-mail: serra@poli.ufrj.br
}

Artigo: Recebido em: 11 de junho de 2013; Versão final aceita em: 11 de outubro de 2013.

RESUMO A busca por padrões de desenvolvimento sustentável que permitam melhor qualidade de vida para a geração atual e para as futuras gerações traz à tona questões como as tendências de esgotamento dos recursos naturais, de aumento da geração de poluição, de escassez de energia, e de drásticas mudanças climáticas. Para dar-se resposta a essas questões e a outros desafios da esfera ambiental, torna-se cada vez mais necessário estudar a viabilidade de adoção de estratégias alternativas nos processos produtivos. A preocupação com os padrões de consumo, que vem atingindo níveis bastante elevados, em todo o mundo, é crescente. Entre os numerosos bens de consumo duráveis comercializados hoje, chama a atenção o caso, extremamente representativo, dos produtos eletroeletrônicos, cujas vendas vêm aumentando significativamente nos últimos anos, praticamente em todos os países, levando, por conseguinte, ao aumento proporcional do uso de recursos naturais e da quantidade de resíduos lesivos ao meio ambiente gerados pela produção e descarte futuro dos produtos. A adoção de estratégias de tratamentos de fim de vida que abordem sistemáticas de ciclo fechado apresenta-se como uma solução para a redução da geração de resíduos e do consumo de recursos naturais. Nesse sentido, a estratégia da remanufatura é considerada, quando possível, a melhor para o enfrentamento da questão. Este trabalho estuda a viabilidade técnica e econômica da adoção dessa estratégia, de forma abrangente e sistemática, na indústria brasileira de refrigeradores, como contribuição para o desenvolvimento sustentável.

Palavras-chave: REEE; remanufatura; refrigeradores.

ABSTRACT The search for sustainable development standards that may allow a better quality of life for the present and the future generations raises issues such as the present trends of depletion of natural resources, the increase in the generation of pollution, energy shortages, and drastic climate changes. In response to these issues and other 
challenges in the environmental sphere, it becomes increasingly necessary to study the feasibility of adopting alternative strategies in production processes. There is a growing concern about consumption patterns, which have reached very high levels all around the world. Among the numerous durable goods marketed today, the highly representative case of electronic products draws the attention of experts and public opinion, since their sales have increased significantly in recent years, virtually in all countries, leading therefore to the proportional increase in the use of natural resources and of the generation of harmful waste for the environment created by the production and final disposal of the products. The adoption of end of life strategies that address closed-loop production structures is probably a good solution to reduce the generation of waste and the consumption of natural resources. In this sense, the strategy of remanufacturing is considered, when possible, as the best strategy to deal with the issue. This work studies the technical and economic feasibility of adopting this strategy, in a comprehensive and systematic way, in the Brazilian refrigerators' industry, as a contribution to sustainable development.

Keywords: WEEE; remanufacturing; refrigerators.

\section{Introdução}

Dados do relatório Estado do mundo, do Worldwatch Institute (2012), mostram que, hoje, são extraídas 60 bilhões de toneladas de recursos anualmente, $50 \%$ a mais do que há apenas 30 anos, e que, entre 1950 e 2010, a produção de metais cresceu seis vezes, e a de petróleo, oito. No mesmo período, o consumo de gás natural aumentou quatorze vezes. Considerando-se a finitude dos recursos naturais não renováveis e os claros sinais de exaustão de muitos deles, esses números mostram, claramente, o desequilíbrio dos modelos de desenvolvimento econômico, social e ambiental praticados atualmente.

Segundo relatório da UNEP (2009), a quantidade de produtos eletroeletrônicos colocados no mercado, anualmente, vem aumentando significativamente, tanto nos países desenvolvidos como nos países em desenvolvimento, gerando enorme pressão sobre os estoques de recursos naturais e produzindo grande volume de resíduos danosos ao meio ambiente. Nesse grupo, chama a atenção a vida útil relativamente curta da maioria dos produtos e a frequente renovação dos modelos oferecidos no mercado.

Como uma das possibilidades de solução ou atenuação das perdas ambientais correspondentes à produção e ao uso desses produtos, destaca-se a adoção de trata- mentos de fim de vida útil que utilizem sistemáticas de "ciclo fechado", que, além dos benefícios ambientais que proporcionam, podem também gerar receitas privadas e ganhos sociais.

O estudo da viabilidade de adoção de políticas integradas de tratamento de resíduos e de gestão da produção que abordem os impactos ambientais ao longo de todo o ciclo de vida dos produtos é crucial para a sustentabilidade. Para isso, torna-se necessária a revisão dos processos produtivos existentes, que podem ser aperfeiçoados por meio de mudanças nos produtos e pela introdução de tecnologias de produção mais eficazes ou ecoeficientes.

Nesse terreno situam-se as alternativas de reciclagem dos materiais (e o seu reprocessamento) ${ }^{1}$, o reuso e a remanufatura dos produtos. A remanufatura mostra-se como uma opção importante, pois recupera os produtos ao final de sua vida útil e reinsere-os na cadeia produtiva, com as mesmas funcionalidades, especificações e garantias do produto novo. Em geral, os produtos remanufaturados têm custos de produção mais baixos que os de um produto fabricado a partir de matérias-primas virgens, uma vez que esse processo torna possível a preservação dos materiais e da energia que foram usados na fabricação original. Esse processo contribui também para a redução dos resíduos depositados nos lixões, aterros ou vias públicas, reduzindo também, consequentemente, a emissão de gases de efeito estufa.

\footnotetext{
${ }^{1}$ Gehin, Zwolinski e Brissaud (2008) observaram que, embora a reciclagem seja atualmente a solução mais comum, está longe de atingir os objetivos do desenvolvimento sustentável.
} 


\section{Desenvolvimento sustentável}

A adoção de padrões de desenvolvimento sustentável está sendo cada vez mais vista como uma necessidade para a garantia do futuro da vida da população e do planeta. A expressão vem de 1987, quando foi publicado o relatório Nosso futuro comum, pela Comissão Mundial do Meio Ambiente e Desenvolvimento das Nações Unidas, conhecido como relatório Brundtland. Nesse relatório, apresentava-se um alerta para a necessidade das nações se engajarem na busca por alternativas ao rumo do desenvolvimento econômico atual com o objetivo de evitar a degradação ambiental e social do planeta (Serra, 2012). Vários autores concordam que, a partir desse relatório, houve um significativo crescimento da consciência geral sobre os danos que o modelo de desenvolvimento econômico atual produz, e o tema entrou no discurso oficial da maioria das nações.

No esteio do Relatório Brundtland realizou-se, em 1992, a Conferência das Nações Unidas sobre o Meio Ambiente e o Desenvolvimento, no Rio de Janeiro, a "Rio 92". A Conferência resultou no documento Agenda 21, que sinalizava para um conjunto de ações para a materialização de mudanças para um novo modelo de desenvolvimento. Vinte anos mais tarde, período em que ocorreram diversas conferências e encontros internacionais na área ambiental, a Conferência "Rio + 20", realizada em 2012, ainda que extremamente limitada quanto aos resultados concretos e enfraquecida pela ausência de líderes mundiais importantes, reafirma, em sua declaração final, intitulada $O$ futuro que queremos, o compromisso com o Desenvolvimento Sustentável.
Esse documento destacou a necessidade de erradicação da pobreza e da fome e reafirmou que a mudança dos padrões inviáveis de consumo e produção para modos sustentáveis, bem como a proteção e gestão dos recursos naturais, são objetivos fundamentais. ${ }^{2}$

Segundo Sonnemann, Castells e Schuhmacher (2003), a sustentabilidade pode ser vista como um triângulo, com cada um de seus lados representando os elementos ambientais, econômicos e sociais. Os autores entendem que, para atingir-se o equilíbrio estável, é necessário que seja dada atenção igual a cada um desses elementos. Nesse sentido, Frosch e Gallopoulos (1989), descrevendo um cenário de um padrão de consumo para toda população do planeta semelhante àquele dos países altamente industrializados, como os EUA e o Japão, constatam que haveria, em menos de uma década, o esgotamento de recursos naturais críticos, como cobre, cobalto, níquel, molibdênio e petróleo, se novos recursos não forem descobertos ou substitutos não forem desenvolvidos. Quanto aos resíduos, considerando-se as taxas de consumo dos EUA, os dez bilhões de habitantes da Terra poderiam gerar 400 bilhões de toneladas de resíduos sólidos a cada ano, o suficiente para enterrar a grande Los Angeles a cem metros de profundidade (Frosch \& Gallopoulos, 1989) ${ }^{3}$.

O interesse por produtos sustentáveis é também recente. A abordagem "berço-ao-túmulo", amplamente utilizada até recentemente, vem sendo modificada para a estratégia "berço-ao-berço"s. Essa nova abordagem faz com que as indústrias não se preocupem somente com a fabricação e o uso de seus produtos, mas também que tenham responsabilidade em fazer com que esses produtos, ao atingirem seu fim de vida útil, sejam

\footnotetext{
${ }^{2}$ Do ponto de vista de Sachs (2012), a Rio+20 deve ser vista essencialmente como uma conferência que traça direções para orientar os países membros das Nações Unidas a redefinirem suas estratégias de longo prazo, para que, em conjunto, possam assegurar, até 2050 (quando seremos nove bilhões de habitantes), condições dignas de vida para a população, e, ao mesmo tempo, mitigar as mudanças climáticas deletérias. E, dessa forma, dois grandes desafios (que estão inteiramente interligados) deverão ser enfrentados: conter as mudanças climáticas e por fim à grande desigualdade nas condições e na qualidade de vida existentes em nações e entre nações. E, mais do que nunca, é necessário combinar justiça social e prudência ambiental.

${ }^{3}$ Os autores apontam, também, para a necessidade de criar-se um modelo de produção mais integrado, onde o consumo de energia e materiais é otimizado, a geração de resíduos é minimizada e os efluentes do processo servem como matéria-prima para outro processo.

4 "Berço-ao-túmulo": compreende o ciclo de vida do produto desde a extração das matérias-primas até seu descarte.

5 "Berço-ao-berço": compreende o ciclo de vida do produto desde a extração das matérias-primas até seu descarte, considerando seu reaproveitamento após o uso, quando retorna ao ciclo produtivo.
} 
reprocessados, tratados e reintroduzidos no mercado, ou que seus materiais sejam reciclados para a fabricação de novas unidades de produto. ${ }^{6}$

\section{Estratégias para of fim da vida dos produtos}

A recuperação dos produtos é denominada pela maioria dos autores como estratégias de fim de vida ou "End-of-Life" (EoL). Essas estratégias se distribuem em alternativas diferentes, com o mesmo objetivo, ou seja, reduzir impactos ambientais, econômicos e sociais. Compõem este conjunto, basicamente, o reuso, a reciclagem e a remanufatura, sendo o reuso ou reutilização a simples volta direta do mesmo item de produto ao uso, como no caso das garrafas de cerveja, de vidro (após a sua lavagem e higienização); a reciclagem refere-se ao reaproveitamento ou o reprocessamento dos materiais que compõem o produto, e a remanufatura o retorno do produto à fábrica para que, após ser testado e sofrer os reparos e substituições de componentes necessários, possa voltar ao mercado com as mesmas especificações do produto novo.

Com a adoção dessas estratégias, garante-se a redução na extração de recursos naturais, a redução do consumo de energia e de água, a extensão do ciclo de vida de produtos e de componentes, a redução na geração do volume de resíduos e, consequentemente, a redução da necessidade de áreas destinadas à implantação de aterros (que geram custos de diferentes tipos).

\section{Remanufatura}

Segundo Hatcher, Ijomah e Windmill (2011), o conceito de reutilização de produtos não é novo. A remanufatura tem sido uma atividade industrial cada vez mais comum desde a Segunda Guerra Mundial, pois, naquele período, a escassez de materiais, principalmen- te na indústria automotiva, fez com que as empresas tivessem que recuperar componentes e peças ao invés de produzi-las. No entanto, foi no início da década de 80 que o interesse em remanufatura como tema de pesquisa acadêmica surgiu, com os estudos do professor Robert Lund (1984), que descreveu o conceito clássico de remanufatura:

Remanufaturar é recuperar um produto usado, descartado ou avariado, às suas especificações originais, e a sua funcionalidade, por meio de um processo industrial.

Existem muitas definições para a remanufatura, em sua maioria variações da mesma ideia básica de refabricação de um produto. Um produto remanufaturado é, geralmente, um produto usado (desgastado ou avariado), que foi restaurado às suas funcionalidades e especificações originais, ou foi modernizado e atualizado para novas especificações. Os produtos usados e descartados que chegam ao processo de remanufatura são denominados "cores" ou "núcleos" para os produtos usados e descartados (Sundin, 2004).

Sundin e Lee (2011) avaliaram o desempenho ambiental da remanufatura em comparação com a reciclagem de material e fabricação de novos produtos. Os resultados mostraram que, em geral, a remanufatura é a melhor opção devido a ganhos ambientais, tais como a redução do esgotamento de recursos, a redução do potencial de aquecimento global e as possibilidades de fechar-se o ciclo dos materiais, garantindo-se também maior segurança no manuseio de materiais tóxicos.

A remanufatura como atividade sistemática vem crescendo em todo o mundo. Nos EUA, a remanufatura está presente nos cinquenta estados da federação. Segundo Lund (2012), em 2012, nos EUA, o banco de dados de remanufaturadores contabilizou 7.000 empresas ativas, que remanufaturam cerca de 125 produtos de áreas diferentes (entre bens de capital ${ }^{7}$ e bens de consumo

\footnotetext{
${ }^{6} \mathrm{O}$ aspecto do consumo sustentável é abordado também pelo Programa das Nações Unidas para o Meio Ambiente (PNUMA), que o define como "o uso de bens e serviços que atendam às necessidades básicas (alimentação, saúde, educação, saneamento, moradia, lazer, etc.) proporcionando uma melhor qualidade de vida, enquanto minimizam o uso dos recursos naturais e materiais tóxicos, a geração de resíduos e a emissão de poluentes durante todo ciclo de vida do produto ou do serviço, de modo que não se coloque em risco as necessidades das futuras gerações".

${ }^{7}$ Bens de capital: maquinário e complexos equipamentos utilizados na fabricação de outros bens, em diversos segmentos industriais.
} 
duráveis $\left.{ }^{8}\right)$. Nesse banco de dados constam três empresas que remanufaturam refrigeradores domésticos. Lund e Hauser (2010) observaram, também, um crescimento significativo das atividades de remanufatura na Europa, e já notam o grande interesse da China nesse mercado?.

Segundo Giuntini e Gaudette (2003), os tipos de produtos que são remanufaturados vão dos complexos sistemas de armas militares, maquinários de mineração e equipamentos agrícolas às máquinas de venda automática. Há, também, alguns casos de remanufatura de bens de consumo duráveis bem sucedidos, como sistemas de automóveis (motores, alternadores, compressores, etc.), computadores, cartuchos de toner para impressoras, máquinas fotocopiadoras, telefones móveis e máquinas fotográficas. Sundin (2004) inclui, também, nessa lista, os eletrodomésticos da linha branca.

O preço de um produto remanufaturado, em geral, equivale de $45 \%$ a $65 \%$ do preço de um produto novo equivalente (Lund, 1984). Estima-se que até $85 \%$ do peso de produtos remanufaturados podem ser obtidos a partir de componentes usados e que tais produtos têm uma qualidade comparável à dos produtos equivalentes fabricados a partir de matérias-primas virgens. Necessita-se de $50 \%$ a $80 \%$ menos energia para obter o produto final remanufaturado e há entre $20 \%$ e $80 \%$ de redução de custos em comparação à fabricação convencional (Sundin et al., 2009).

Em comparação com a produção de um produto completamente novo, as emissões de GEE (gases do efeito estufa) e o consumo de energia resultantes das atividades de remanufatura são muito inferiores, e a quantidade de energia necessária para produzir um refrigerador novo é cerca de 50 vezes maior do que a energia necessária para remanufaturá-lo (Lindhal et al., 2006).

As atividades de remanufatura melhoram, também, a imagem ambiental das empresas, além de gerar lucros com a venda dos produtos remanufaturados. Em geral, a remanufatura emprega mais trabalhadores que a produção de produtos novos e, por isso, tem uma contribuição significativa para as comunidades onde o desemprego é alto.

Mais ainda, a remanufatura requer investimento de capital relativamente baixo, uma vez que equipamentos utilizados na fabricação das peças, que normalmente são de alto custo, são desnecessários nesse contexto e o processo utiliza basicamente ferramentas manuais (em alguns casos, também máquinas com jato de vapor para limpeza e alguns equipamentos para os testes de desempenho). As necessidades de capital de giro, por sua vez, são também menores, porque a matéria-prima principal é um produto usado, cujo custo de obtenção é, em geral, bastante baixo.

\subsection{O processo de remanufatura}

Sundin (2004) descreve o processo de remanufatura em oito passos básicos, que podem ser alterados de acordo com cada tipo ou modelo de produto. São eles: a coleta dos "núcleos"; a inspeção e a identificação de falhas; a desmontagem do produto; a limpeza e o armazenamento das partes ou peças do produto; o reparo das partes ou peças avariadas, e substituição de partes ou peças novas, quando for necessário; a remontagem do produto; e os testes de verificação de desempenho, para a garantia de que as especificações sejam as mesmas de um produto novo.

\subsection{Fatores motivadores e barreiras para a adoção da remanufatura pelas empresas}

Segundo Lindhal et al. (2006), são três os principais fatores motivadores para que as empresas adotem a remanufatura como atividade sistemática: a demanda do mercado, a legislação e as questões ambientais. A demanda é estimulada pela possiblidade de aquisição de produtos de qualidade com as mesmas caraterísticas

\footnotetext{
${ }^{8}$ Bens de consumo duráveis: são aqueles bens que apresentam duração média de vida útil de alguns anos a algumas décadas. São automóveis, eletrodomésticos, máquinas e equipamentos industriais, aviões, navios, dentre outros.

${ }^{9} \mathrm{Na}$ Europa, segundo Sundin (2006), as empresas, cada vez mais, aumentam seus interesses quanto ao sistema de remanufatura e às atividades associadas, como a logística reversa. Devido às pressões da legislação, os interesses de reutilização dos produtos vêm aumentando, e empresas de remanufatura em novos setores industriais, e em novos países europeus, vêm crescendo também.
} 
dos produtos novos e a preços mais acessíveis ${ }^{10}$; a legislação, de um modo geral, vem gerando pressões sobre as empresas para a adoção de alternativas para a redução da geração de resíduos e de outros impactos ambientais de seus produtos e processos de produção, como no caso das Diretivas ambientais europeias ${ }^{11}$, cujos efeitos, para Ostlin (2008), podem ter um significativo impacto motivador para a indústria da remanufatura.

As dificuldades e barreiras para a implantação de rotinas de remanufatura, no entanto, são numerosas. As empresas de remanufatura estão sujeitas a incertezas com relação à qualidade, quantidade e frequência no recebimento dos "núcleos", o que torna o planejamento das atividades mais difícil. A esse respeito, Lund (1984) ressalta que, por definição, quase todos os "núcleos" que chegam para remanufatura estão defeituosos, e que ter, ao final do processo, produtos de qualidade equivalente à de produtos novos, a partir de "núcleos" de qualidade desconhecida, é o principal teste de capacitação da empresa à remanufatura, o que aponta para a necessidade de as empresas disporem de uma rede de logística reversa ${ }^{12}$.

A cultura dos consumidores pode afetar a adoção da remanufatura, pois os produtos remanufaturados são ainda vistos, em muitos segmentos da sociedade, como inferiores ou não confiáveis ${ }^{13}$. Outros problemas estão relacionados com o projeto dos produtos, que, normalmente, não leva em conta as questões ambientais na fase de concepção. Segundo Ijomah et al. (2007), a maioria dos produtos apresenta baixa remanufaturabilidade porque não foi projetada com essa finalidade. A grande diversidade de produtos e de modelos de produtos existentes é também um obstáculo. Nesse sentido, uma importante abordagem para evitar ou reduzir os problemas na remanufatura é o Projeto para Remanufatura ou Design for Remanufacturing (DfReman). Esta abordagem é uma parte do Projeto para o Meio Ambiente (DfE) e pode ter um grande impacto na eficiência da remanufatura.

Gray e Charter (2007) descreveram o DfReman como uma série de atividades, incluindo projeto para coleta dos "núcleos", projeto para o meio ambiente, projeto para desmontagem, projeto para ciclos de vida múltiplos e projeto para atualização. Muitos aspectos devem ser considerados, tais como a facilidade para desmontagem, triagem, limpeza, reparo e substituição de peças, remontagem e testes, para que haja mais facilidade e eficiência no processo de remanufatura. Essa maior facilidade é reforçada, segundo Hatcher et al. (2011), quando o próprio fabricante $(O E M)^{14}$ remanufatura seus produtos e aplica, na fase de projeto, os conceitos de DfReman, obtendo redução do desperdício de material e dos tempos de desmontagem e gerando, ainda, maior rentabilidade na operação.

A aplicação do conceito pode ser exemplificada na fase de projeto com a utilização de componentes modulares (o que permite desmontar e remontar os produtos com muito mais facilidade e maior rapidez), a padronização de fixadores de componentes ou peças (o uso de conectores que não utilizem soldagens, parafusos e outros tipos de fixação, que possibilitam o uso de ferramentas simples para facilitar as etapas de desmontagem e montagem), e a padronização das interfaces dos componentes (um menor número de peças é necessário para produzir uma grande variedade de produtos similares).

\section{Ecologia industrial}

Como elemento importante para o estudo de alternativas sustentáveis para a produção industrial, destaca-se a abordagem da "ecologia industrial". Grae-

\footnotetext{
${ }^{10}$ Cooperativas de coleta e serviços especializados em logística reversa são alguns dos mercados que podem ser criados com as atividades da remanufatura.

${ }^{11}$ Normas da União Europeia para a área ambiental, acordadas entre todos os países-membros.

${ }^{12}$ Leite (2009) define Logística Reversa como a área da logística empresarial que planeja, opera e controla o fluxo e as informações logísticas correspondentes, do retorno dos bens de pós-venda e de pós-consumo ao ciclo de negócios ou ao ciclo produtivo, por meio dos canais de distribuição reversos, agregando-lhes valores de diversas naturezas: econômico, de prestação de serviços, ambiental, legal, logístico, de imagem corporativa, dentre outros.

${ }^{13}$ Este fato aponta para a necessidade de os remanufaturadores serem mais agressivos em familiarizar os formuladores de políticas com os benefícios que suas empresas podem auferir, alegando que podem fazer os bens materiais durarem mais, ajudando a preservar as riquezas naturais. ${ }^{14}$ OEM: Original Equipment Remanufacturer.
} 
del e Allenby (1995) definiram o conceito de ecologia industrial como:

[...] o meio pelo qual a humanidade pode deliberada e racionalmente se aproximar e manter uma capacidade de carga desejável, continuando sua evolução econômica, cultural e tecnológica. $\mathrm{O}$ conceito requer que um sistema industrial não seja visto isoladamente de seus sistemas adjacentes, mas, em conjunto com eles. É uma visão sistêmica em que se busca otimizar o ciclo total de materiais a partir do material virgem, do material acabado, do componente, do produto, do produto obsoleto, até o descarte final. Fatores a serem otimizados incluem recursos, energia e capital.

De forma análoga ao ecossistema, os sistemas industriais, sob a ótica da ecologia industrial, são vistos como circuitos fechados de materiais onde os resíduos gerados em um processo podem ser utilizados como insumos em outro processo. O conceito de resíduo, assim, deixa de existir, pois estes se tornam novas matérias-primas.

O conceito de Ecologia Industrial passou a ser amplamente divulgado a partir de 1989 quando Frosch e Gallopoulos publicaram um artigo intitulado "Strategies for Manufacturing", onde argumentam ser possível desenvolver métodos de produção com menor impacto ao ambiente, substituindo os processos isolados por sistemas integrados, que chamaram de ecossistemas industriais, com o aproveitamento dos resíduos como novos insumos ${ }^{15}$. Esta abordagem pode ser aplicada dentro da própria indústria, entre indústrias, e em nível regional ou global (Chertow, 2000).

Contribuem para a construção da Ecologia Industrial ferramentas como a Prevenção da Poluição, a
Produção mais Limpa e o Projeto para o Meio Ambiente (Design for Environment), que contribuem para mudar a forma como os produtos são fabricados, melhorando o desempenho ambiental da indústria. Entre indústrias, podem ser utilizados a Avaliação do Ciclo de Vida (ACV), a simbiose industrial e os parques industriais ecológicos e, quanto ao nível regional ou global, podem ser usados a análise do fluxo de materiais e energia, os planos de desenvolvimento regionais ou nacional e a avaliação ambiental estratégica, dentre outros.

O Ciclo de Vida é definido como o conjunto de etapas necessárias para que um produto cumpra sua função. Esta metodologia foi desenvolvida para a melhoria dos processos e produtos industriais e compreende a identificação dos fluxos de materiais, de energia e de emissões de poluentes ao longo de todo o processo produtivo e de todo o período em que o produto é usado, cobrindo, assim, todas as operações a que o produto é submetido, desde a produção das matérias-primas de seus componentes até o seu descarte final. ${ }^{16} \mathrm{Na}$ definição da Society of Environmental Toxicology and Chemistry ${ }^{17}$, a avaliação do ciclo de vida

[...] é o processo objetivo de avaliar as cargas ambientais associadas com um produto, processo ou atividade através da identificação e quantificação do uso de energia e matéria e de emissões ambientais, o impacto do uso da energia e material e das emissões, e a determinação de oportunidades de melhorias ambientais. A avaliação inclui todo o ciclo de vida do produto, processo ou atividade, envolvendo extração e processamento de matérias-primas, fabricação, transporte, e distribuição, uso, reuso, manutenção, reciclagem, e disposição final.

Assim, um estudo de ACV consiste da identificação das entradas de matéria e de energia do meio ambiente

\footnotetext{
${ }^{15}$ Gianetti e Almeida (2006) afirmam que, na lógica da Ecologia Industrial, é possível reorganizar os fluxos de matérias e de energia que circulam pelo sistema industrial, de maneira a torná-lo um circuito quase totalmente fechado e compatível com a vida do planeta.

${ }^{16}$ Esta definição difere da outra acepção dada à expressão, a do "caminho" percorrido pelo produto ao longo de sua existência, desde a sua concepção até a sua retirada do mercado. A maioria dos autores identifica, nessa acepção de Ciclo de Vida, quatro fases, a saber: a introdução, com a produção de baixo volume, o crescimento das vendas, a maturidade do produto, com vendas estáveis por um período maior de tempo, e o possível declínio das vendas, que pode culminar na retirada do produto do mercado.

${ }^{17}$ A SETAC (Society for Environmental Toxicology and Chemistry) foi fundada em 1979, sendo o primeiro organismo em nível internacional que reuniu todos os estudos realizados, com objetivos de sistematizar uma metodologia e critérios para o desenvolvimento da ACV, e sua contribuição teve um papel decisivo no aperfeiçoamento da ferramenta de ACV, criando as bases necessárias para a construção de metodologias padronizadas de uso universal. A SETAC é atualmente o principal fórum mundial de debates e discussões sobre a técnica de ACV.
} 
para o sistema que constitui o ciclo de vida do objeto do estudo e das saídas de matéria e energia desse sistema para o meio ambiente, e da avaliação dos potenciais impactos ambientais associados a essas entradas e saídas (Silva \& Kulay, 2006). AACV é um instrumento de gestão ambiental que permite às organizações conhecerem as interfaces ambientais dos materiais, dos processos e dos produtos, podendo, a partir dessas informações, desenvolver novos produtos e detectar melhorias a serem aplicadas e considerar as questões ambientais associadas aos sistemas de produção, contribuindo para melhorar o entendimento dos aspectos ambientais relacionados aos processos produtivos de uma forma mais abrangente, identificando oportunidades para melhorias ${ }^{18}$ (Chehebe, 1997).

Anderi e Kulay (2006) afirmam ser possível dividir as aplicações da ACV em duas vertentes: a comparação do desempenho ambiental de produtos que cumpram uma mesma função e a identificação de oportunidades de melhoria de desempenho ambiental. Os autores ressaltam ainda que a ACV é a única técnica de gestão ambiental que possibilita a comparação do desempenho ambiental entre produtos. ${ }^{19}$

No Brasil estão em vigor duas normas de avaliação do ciclo de vida publicadas pela ABNT, que têm como referência as normas equivalentes da International Organization for Standardization - ISO: ABNT NBR ISO 14040:2009 - "Gestão Ambiental - Avaliação do ciclo de vida - Princípios e estrutura"; e ABNT NBR ISO 14044:2009 - "Gestão Ambiental - Avaliação do ciclo de vida - Requisitos e orientações".

Devido à complexidade da metodologia de $\mathrm{ACV}$, os critérios adotados na definição da coleta de dados podem influenciar significativamente nos resultados finais da avaliação. O elevado custo da execução de uma ACV, devido, principalmente, ao número de dados envolvidos, é um dos obstáculos na difusão do uso dessa ferramenta ${ }^{20}$.

O Projeto para o Meio Ambiente ou DfE (Design for the Environment), também conhecido como eco-design, analisa todo o ciclo de vida do produto e propõe alterações no projeto para minimizar seu impacto ambiental, desde a fabricação até o descarte. É uma abordagem que permite às empresas buscar o desenvolvimento de produtos mais sustentáveis e com melhor desempenho ambiental.

O DfE aborda os problemas ambientais associados a um determinado produto ainda na fase de concepção, ou seja, considera a variável ambiental como um dos requisitos do produto, além dos objetivos de desempenho, qualidade, funcionalidade e custo. A desmaterialização do produto (menor uso de materiais) e a retirada dos materiais tóxicos utilizados, com destaque para as substâncias perigosas, sem comprometer a função a que o produto se destina, são elementos essenciais do $D f E$ (Sonnemann et al., 2003). Segundo Graedel e Allenby (1996), o DfE compreende também as atividades de prevenção à poluição e do projeto do processo produtivo, sendo a primeira direcionada a processos e produtos, minimizando seu impacto ambiental, com ações como a prevenção de vazamentos, a conservação de energia e melhorias nas embalagens, e a segunda voltada para produtos já existentes, incluindo ações como o desenvolvimento de modularidade, a minimização da diversidade de materiais e a melhoria na eficiência energética.

O Projeto para Remanufatura, ou Design for Remanufacturing, é uma derivação do $D f E$ que pode gerar vários benefícios que viabilizem e tornem o processo produtivo como um todo mais eficiente e eficaz. Projetar para o reuso, para a remanufatura e para reciclagem, nesta ordem de preferência, são escolhas que podem ser fei-

\footnotetext{
${ }^{18} \mathrm{Na}$ mesma linha, Silva e Kulay (2006) afirmam que os produtos são manufaturados com o objetivo de cumprir uma função. Isso significa que o potencial de impacto ambiental referente, além de sua manufatura, inclui sua distribuição, sua utilização pelo consumidor e sua destinação após o uso - sua reutilização, seu possível reaproveitamento e seu descarte -, atividades que podem impactar significativamente o meio ambiente, cujos respectivos impactos devem, desse modo, ser considerados na avaliação de seu desempenho ambiental.

${ }^{19}$ Por sua vez, Almeida e Giannetti (2006) ressaltam que, embora a comparação de desempenho ambiental seja bastante utilizada entre as aplicações da ACV, o emprego dessa técnica para melhorar produtos é mais importante, pois pode identificar elementos que contribuem para a minimização de impactos ambientais.

${ }^{20}$ A coleta de dados pode ser inviabilizada pelos mais diversos motivos, como o desinteresse de empresas ou de setores produtivos e a exigência da preservação da confidencialidade de uso de determinados insumos e tecnologias. Há, no entanto, programas proprietários que disponibilizam bancos de dados que viabilizam e reduzem as limitações encontradas, normalmente, nos estudos da ACV.
} 
tas durante o desenvolvimento do produto. Projetos para reuso e para remanufatura podem garantir que a maioria dos componentes será reutilizada. Neste caso, como se pretende que o produto e seus componentes mantenham sua forma original, uma quantidade mínima de energia será consumida no processo. Quanto mais complexa for a montagem do produto, maior será o número de etapas para a desmontagem e, consequentemente, mais difícil seu reaproveitamento, mas a facilidade de desmontagem pode ser prevista no projeto (Junior, Giannetti \& Almeida, 2003).

É importante ressaltar que a integração entre meio ambiente e tecnologia, em todas as operações de uma empresa, representa uma mudança significativa e fundamental para a organização. Esta mudança requer que as questões ambientais se tornem estratégicas para a empresa, assim como as condições competitivas e econômicas o são ${ }^{21}$.

\section{Os refrigeradores}

O refrigerador é um bem de consumo durável que tem um expressivo volume de produção. É um produto maduro $^{22}$, sem que haja qualquer previsão de introdução de alterações significativas em sua concepção, e nem tampouco há perspectivas de sua substituição por outro produto. Segundo dados do relatório Refrigeration Technical Options Committee - RTOC (UNEP, 2010), cerca de 100 milhões de refrigeradores e congeladores domésticos são produzidos, anualmente, no mundo. A maioria é usada para o armazenamento de alimentos nas residências, e os volumes típicos variam de 20 a 850 litros por unidade. Ainda conforme o relatório, a distribuição etária dos produtos instalados é extremamente ampla, com estimativas médias variando de 9 a 19 anos de uso. Com a vida longa do produto e o alto volume de produção anual, a estimativa é que o número de unidades instaladas no mundo seja de aproximadamente 1,8 bilhão, entre refrigeradores e congeladores domésticos. Estima-se também que $80 \%$ desse total referem-se somente a refrigeradores domésticos.

Dados do IBGE, divulgados em 2012, referentes à Pesquisa Nacional por Amostra de Domicílios - PNAD - mostraram que, no ano de 2011, havia 58,7 milhões de unidades de refrigeradores domésticos no Brasil, atingindo um percentual de $95,8 \%$ dos domicílios. O relatório "Resultados PROCEL 2012", com dados referentes às vendas de refrigeradores, mostra que, em 2010, foram vendidas no Brasil 6,62 milhões de unidades.

Um refrigerador é composto de um gabinete, portas, acessórios (prateleiras, módulos, gavetas, etc.) e do circuito elétrico de refrigeração, composto pelo compressor, fluido refrigerante e outros componentes. A composição é basicamente de metais (aço, cobre e alumínio), plásticos (espumas do isolamento térmico, revestimento interno das portas e outros plásticos), vidros, agente expansor, fluido refrigerante, componentes elétricos e eletrônicos e outros menos expressivos. Os metais têm a maior contribuição na composição do refrigerador.

Como ilustração, um modelo de refrigerador com duas portas, pesando $89 \mathrm{~kg}$, com capacidade de armazenamento de 300 litros (incluindo o congelador), que utiliza o isobutano R-600a como fluido refrigerante e o ciclopentano como agente expansor, tem sua composição distribuída da seguinte forma: $60 \%$ de aço, $2,8 \%$ de cobre, $1,9 \%$ de alumínio, $10,5 \%$ de espumas de isolamento térmico, $16,1 \%$ de outros plásticos, $5,8 \%$ de vidros, $0,4 \%$ de agente expansor, $0,2 \%$ de fluido refrigerante, $0,6 \%$ de componentes eletrônicos e 1,7\% de outros materiais, conforme dados do Certificado de Declaração Ambiental do Produto - EPD ${ }^{23}$, para o modelo ER 8199B da Electrolux, produzido na Suécia.

\footnotetext{
${ }^{21}$ Há, entretanto, além das dificuldades técnicas, barreiras diversas à implementação do $D f E$, de natureza cultural ou organizacional. Para Graedel e Allenby (1996), é a necessidade de implementar mudanças fundamentais dentro de uma organização complexa, e não o desenvolvimento de tecnologias necessárias para as mudanças, o maior desafio para implementar o $D f E$.

${ }^{22}$ Considerando-se as fases da existência de um produto, comumente referenciadas, na Literatura, como de concepção, introdução no mercado, crescimento das vendas, maturidade (em geral de duração mais longa) e declínio (que pode levar à sua retirada do mercado).

${ }^{23}$ EPD (Environmental Product Declaration - Declaração Ambiental do Produto) é um conjunto de informações, relativas aos aspectos e impactos ambientais de um produto ao longo do seu ciclo de vida, baseado na Avaliação de Ciclo de Vida.
} 
No Brasil, segundo dados do INMETRO, a maioria dos fabricantes incorporou o hidrocarbono ciclopentano na função de agente isolante térmico e expansor e o hidrofluorcarbono (HFC) R-134a na função de gás refrigerante. Algumas empresas já utilizam o isobutano HC-600a ou R-600a, em alguns modelos, denominando-os “100\% ecológicos”. Há refrigeradores antigos, em uso, que ainda utilizam os CFCs (R11 e R12), apesar de essas substâncias não serem mais produzidas. Em 2008, segundo informações da Associação Nacional de Fabricantes de Produtos Eletroeletrônicos (ELETROS), estimava-se que esse número chegava a 11 milhões de unidades, concentrado nas classes de baixa renda.

Os gabinetes e as portas dos refrigeradores são constituídos de aço laminado na parte externa e de poliestireno de alto impacto (PSAI ou HIPS - High Impact Polystyrene) na parte interna, sendo os espaços entre essas duas partes preenchidos com espumas rígidas de poliuretano (PUR). A PUR apresenta excelentes propriedades para isolamento térmico e também provê alta resistência estrutural para os refrigeradores. Segundo Lopes e Becker (2012), cerca de 60\% em volume desse material, no mercado brasileiro, estão concentrados no setor de refrigeração doméstica.

Os refrigeradores, ao fim de sua vida útil, quando são descartados, passam a ser considerados Resíduos de Equipamentos Eletroeletrônicos (REEE) e devem ser tratados adequadamente para evitar problemas ao meio ambiente e também o desperdício de materiais. As questões que envolvem os problemas do descarte dos equipamentos eletroeletrônicos, especialmente os produtos de linha branca, como os refrigeradores, devido à sua composição, ao volume que ocupam quando descartados inadequadamente e aos problemas ambientais decorrentes, tornaram-se, há algum tempo, tema de preocupação mundial. Muitos países procuraram desenvolver mecanismos para solucionar essas questões, por meio de leis ou acordos, de maneira a promover a valorização desse material com o uso da remanufatura e da reciclagem. Retornos econômicos para as empresas e de proteção ambiental em geral, além do desenvolvimento de produtos e tecnologias que facilitam os processos de reaproveitamento são alguns dos ganhos obtidos.
Os países europeus têm maior tradição no gerenciamento e controle desses resíduos e seguem as orientações das Diretivas europeias específicas para os REEE. Normalmente, dado o reconhecido desenvolvimento da União Europeia, em geral, na área ambiental, essas diretivas são a base de orientações para muitos outros países quanto a medidas para o tratamento desse tipo de resíduo. No Brasil, ainda são discutidas as questões do tratamento dos resíduos sólidos de maneira geral e somente em 2010 foi regulamentada uma lei nacional, a Lei dos Resíduos Sólidos. ${ }^{24}$ Quanto aos REEE, especificamente, há um grupo de trabalho envolvendo vários setores do governo, da indústria e do comércio, que estuda e discute o assunto para viabilizar a aplicação da lei.

\subsection{A política nacional de resíduos sólidos (PNRS)}

Após quase vinte anos tramitando no Congresso Nacional, a PNRS foi aprovada por meio da Lei $\mathrm{n}^{\circ}$ 12.305 , de 02 de agosto de 2010, e regulamentada pelo Decreto $n^{\circ} 7.404$, de 23 de Dezembro de 2010. Ainda estão sendo discutidas, no entanto, algumas questões relativas aos REEE. Um grupo de trabalho chamado "GTT-REEE - Grupo Técnico Temático de Resíduos de Equipamentos Elétricos e Eletrônicos", coordenado pelo Ministério de Desenvolvimento, Indústria e Comércio Exterior (MDIC), envolvendo setores do governo, da indústria e do comércio, busca soluções que viabilizem a logística reversa e a responsabilidade estendida do fabricante, de maneira que possam ser obtidos benefícios com a recuperação desses produtos em final de vida. Uma das atribuições desse grupo é elaborar uma proposta de modelagem para a logística reversa dos resíduos de equipamentos eletroeletrônicos.

Do convênio firmado entre a Agência Brasileira de Desenvolvimento Industrial - ABDI - e o MDIC resultou um estudo com objetivo de subsidiar o GTT-REEE na formulação de um acordo setorial para a implantação do processo de logística reversa para o setor de eletroeletrônicos. Esse estudo, disponível no site do MDIC, intitula-se "Logística Reversa de Equipamentos

${ }^{24}$ Lei no 12.305 , de 02 de agosto de 2010. 
Eletroeletrônicos, Análise de Viabilidade Técnica e Econômica". Nele destacam-se alguns pontos importantes para o entendimento do modelo proposto, que apontam para os direcionamentos considerados mais adequados para a resolução dos pontos críticos de decisão na modelagem da logística reversa de resíduos eletroeletrônicos.

A Lei dos Resíduos Sólidos (PNRS) pode gerar mudanças, se colocada em prática com empenho e comprometimento dos gestores e de toda a cadeia produtiva envolvida, incluindo-se os consumidores. A aplicação da lei poderá abrir boas oportunidades de negócios e dar uma solução inteligente para os resíduos gerais e, em particular, para os REEE. A PNRS pode ser uma boa oportunidade para o desenvolvimento da remanufatura no Brasil, dado que as inovações dessa lei exigirão alterações na conduta dos fabricantes quanto ao retorno de produtos, pois os responsabiliza pelo seu recolhimento com a logística reversa, incentivando, assim, o reuso e a reciclagem. As obrigações com a responsabilidade ambiental levam ao fechamento dos ciclos dos materiais e tendem a fazer com que essas empresas/fabricantes tomem decisões que considerem as questões ambientais, econômicas e sociais em relação ao retorno dos seus produtos.

\subsection{A manufatura reversa de refrigeradores}

A Norma ABNT NBR 15833:2010, específica sobre Manufatura Reversa de aparelhos de refrigeração, prescreve os procedimentos para o transporte, armazenamento e desmontagem com reutilização, recuperação dos materiais recicláveis e destinação final de resíduos dos aparelhos de refrigeração. A Norma é aplicável a todos os estabelecimentos que realizam ou venham a realizar procedimentos de manufatura reversa de aparelhos de refrigeração, inclusive quando estas operações são realizadas nas próprias instalações dos fabricantes.
A Norma define Manufatura Reversa de aparelhos de refrigeração como:

[...] todas as ações utilizadas para o armazenamento e processamento dos aparelhos de refrigeração, com a finalidade de recuperação da maior quantidade possível de fluidos refrigerantes, agentes de expansão, fluido lubrificante e demais substâncias e materiais, bem como a promoção da destinação final adequada dos resíduos.

O governo brasileiro tem um programa de substituição de refrigeradores obsoletos por refrigeradores energeticamente eficientes que utilizam substâncias que não prejudicam a camada de ozônio. Esse programa integra as concessionárias de energia elétrica, os fabricantes dos refrigeradores e os lojistas e é uma resultante da lei que determina que as concessionárias de energia elétrica dispensem um percentual de seus lucros em programas ou ações de eficiência energética para a população de baixa renda.

Desde 2005, é mandatório que cada concessionária de energia invista parte dos recursos dos seus programas de eficiência ${ }^{25}$ em programas de eficiência energética do lado da demanda voltados para a população de baixa renda beneficiada pela Tarifa Social ${ }^{26}$ de energia elétrica. Grande parte desses recursos vem sendo utilizada na substituição de refrigeradores obsoletos, troca de lâmpadas incandescentes por fluorescentes, reparos ou instalação de rede elétrica adequada e aquecimento solar (Jannuzzi, 2007).

\section{Avaliação da possibilidade de adoção da estratégia de remanufatura para o caso dos refrigeradores}

$\mathrm{Na}$ avaliação do ciclo de vida (ACV) dos refrigeradores há um consenso, tanto dos fabricantes desses

\footnotetext{
${ }^{25}$ A lei n ${ }^{\circ}$ 9.991/2000 refere-se à obrigação das concessionárias de energia elétrica de investirem uma parcela de suas receitas operacionais líquidas em programas de P\&D e de eficiência energética. Esses programas são submetidos ao órgão regulador, ANEEL, para aprovação. A lei n ${ }^{\circ}$ 12.212/2010 alterou o Art. 11 da lei no 9.991/2010: V - as concessionárias e permissionárias de distribuição de energia elétrica deverão aplicar, no mínimo, $60 \%$ (sessenta por cento) dos recursos dos seus programas de eficiência para unidades consumidoras beneficiadas pela Tarifa Social. ${ }^{26}$ A Tarifa Social de Energia Elétrica é um desconto na conta de energia elétrica destinado às famílias inscritas no Cadastro Único com renda de até meio salário mínimo per capita. É resultante da Lei ${ }^{\circ} 12.212$, de 20 de janeiro de 2010.
} 
produtos quanto da literatura pertinente ao assunto, de que é durante sua fase de uso que o refrigerador apresenta maior impacto ambiental, que se agrava com o declínio na eficiência energética durante o tempo de vida do produto ${ }^{27}$.

Considerando-se o objetivo de alcançar-se a sustentabilidade, com a preservação dos recursos naturais e a redução na geração de resíduos e da poluição, as fases de produção e fabricação dos refrigeradores também devem ser avaliadas, uma vez que seus impactos são bastante expressivos. O processo de extração de matérias-primas envolve escavações de grandes quantidades de terra e de rochas, gerando grandes quantidades de resíduos, efluentes líquidos, gases de efeito estufa e material particulado, além da degradação da paisagem do local. O uso intensivo de água e a exaustão dos recursos renováveis são também impactos negativos ao meio ambiente gerados nessa fase.

Após a extração das matérias-primas, é necessário o processamento e o beneficiamento desses materiais, que comporão as peças e componentes para a fabricação do produto na indústria. Na fabricação é necessária a utilização de máquinas, energia, materiais químicos e de transporte para as indústrias, dentre outros processos que também geram resíduos, gases de efeito estufa, efluentes líquidos, material particulado, poluição etc.

$\mathrm{O}$ processo de remanufatura exige a desmontagem do produto e os refrigeradores, devido às suas características de fabricação, geram algumas dificuldades para o desmonte. Giannetti e Almeida (2006) relatam as etapas e dificuldades encontradas em um estudo realizado em 2002, na Universidade Federal de Santa Catarina, sobre a desmontagem manual de um refrigerador novo, de uma porta, com capacidade de 293 litros. No experimento, o refrigerador foi desmontado com a utilização de ferramentas como chaves de fenda, chaves tipo canhão, alicates de corte, serra manual, lâmina metálica, formão, espátula, facão e martelo. Foi elaborada uma escala com grau de dificuldade variando de 1 a 5 , sendo "1" extremamente fácil, " 2 " fácil, "3" difícil, "4" muito difícil e " 5 " extremamente difícil.
Ao analisar os resultados, os pesquisadores observaram que as operações de remoção da espuma rígida (PUR) do isolamento térmico e a desmontagem do gabinete foram consideradas as de maior grau de dificuldade e as mais demoradas. A operação de separação da PUR mostrou-se extremamente difícil de executar e de completar, mostrando que é necessário desenvolver-se uma solução para esse problema.

$\mathrm{Na}$ fabricação do gabinete e das portas, a espuma do isolamento térmico é injetada entre a parte externa do refrigerador (aço) e o plástico do revestimento interno, de maneira a se adequar às formas do refrigerador e aderir aos materiais (aço e plástico). Mas, na desmontagem, devido ao modo de fabricação atual, torna-se difícil a separação desses materiais visando à remanufatura.

O compressor é o componente principal no desempenho do funcionamento e na operação do refrigerador e suas características e especificações determinam, além do bom funcionamento do refrigerador, o consumo de energia elétrica. Quanto mais eficiente o compressor, menor o consumo de energia. No Brasil, segundo a Norma ABNT NBR: 15833:2010, os compressores devem ser retirados dos refrigeradores e encaminhados para descaracterização, recuperação dos materiais e destinação final das demais frações que não forem recuperáveis. Segundo a Norma, somente o fabricante original do equipamento pode reutilizar compressores provenientes de aparelhos pré-consumo (novos). Aqueles provenientes de aparelhos pós-consumo (usados e seminovos) não poderão ser reutilizados. A Norma não é clara quanto às definições do que é considerado pré-consumo e o que é considerado pós-consumo (no caso dos semi-novos) e abre espaço para suposições diversas.

O desgaste dos refrigeradores, ao longo de sua vida útil, pode ter, como consequências, o comprometimento do seu desempenho e, também, o aumento do consumo de energia elétrica. $O$ grau do comprometimento depende dos hábitos de uso e da tecnologia utilizada e quatro fatores podem ser citados como os mais importantes para o desempenho do refrigerador: a vedação (as borrachas de vedação das portas), o isolamento térmico, o termostato e o compressor.

\footnotetext{
${ }^{27}$ No entanto, é certo que avanços na tecnologia podem gerar o desenvolvimento de componentes mais eficientes que reduzam esse impacto indesejado.
} 
Um levantamento junto a dois fabricantes de refrigeradores no Brasil mostra que, até os cinco anos de idade, os equipamentos não têm qualquer comprometimento no desempenho, mas, a partir dos cinco anos de uso, os refrigeradores começam a apresentar redução de eficiência devido ao desgaste dos quatro fatores citados anteriormente (Cardoso, 2008). No contexto atual, pode-se afirmar que a remanufatura de refrigeradores pode ser viável econômica e tecnicamente sem que fique comprometida a eficiência energética do produto, nos casos de produtos que estão na garantia e apresentam problemas que a assistência técnica não resolve, de produtos que sofreram algum dano ou avaria no transporte ou no armazenamento e de produtos que foram utilizados como serviços (a função do produto foi comercializada, e não o produto físico).

O que caracteriza os casos apresentados (produtos com pouco ou nenhum uso) é a garantia de que a tecnologia utilizada é praticamente a mesma que está embarcada nos produtos recém fabricados. Esse fator é importante para que o processo seja tecnicamente viável, uma vez que qualquer componente que necessite ser substituído poderá ser prontamente atendido, pois terá suporte técnico. Nesse caso, poderão ser utilizados componentes ou peças novos e/ou remanufaturados.

Para os casos indicados acima, os próprios fabricantes dos produtos ou empresas credenciadas e autorizadas por estes realizam o processo de remanufatura. É importante ressaltar que, quando o próprio fabricante realiza a remanufatura, são obtidos ganhos, no caso geral, em diferentes aspectos, pois o fabricante tem o conhecimento detalhado de todas as fases de projeto do produto. Com o retorno do produto às instalações da fábrica, torna-se possível, assim, identificar-se mais facilmente quais componentes apresentam problemas e a empresa pode, a partir desse conhecimento, melhorar o desempenho do produto ou do processo.

Sundin (2004) relata um caso de sucesso de remanufatura de eletrodomésticos numa fábrica, na Suécia, referente aos casos descritos acima, em que, em termos gerais, a atividade trouxe boas oportunidades para a empresa porque contribuiu para melhorar sua imagem ambiental e gerou lucros financeiros. Além disso, muitos equipamentos avariados, sem condições de reparo fora da fábrica, foram recuperados e vendidos aos varejistas com status de produtos novos, a preços menores. Ao final da pesquisa, o autor destacou o comentário de um dos principais gerentes da empresa estudada, que afirmou ser a remanufatura, no caso de tratamento de fim de vida para os equipamentos, uma das melhores opções possíveis para as empresas.

Mas, para a hipótese de adoção dessa sistemática em larga escala, no Brasil, nos marcos do padrão de fabricação atual, a remanufatura de refrigeradores não parece viável. O principal obstáculo são as dificuldades técnicas encontradas no desmonte dos equipamentos, somadas à impossibilidade de reaproveitamento dos compressores usados (salvo nos casos descritos acima), oriundas do fato de que os refrigeradores produzidos atualmente não são projetados para a remanufatura, o que reduz sobremaneira a margem de reaproveitamento dos refrigeradores usados para esse fim.

A grande diversidade de modelos, com baixo grau de padronização, dificulta em muito o processo de remanufatura. Outras barreiras relevantes encontradas no Brasil são a falta de uma oferta regular de refrigeradores usados para utilização como matéria-prima para a remanufatura e a não existência, em escala significativa, de uma cultura dos consumidores receptiva e sem preconceitos quanto à confiabilidade dos produtos remanufaturados que permita essa implantação. No plano da estrutura industrial, a adoção da remanufatura em grande escala cria também dificuldades para que as empresas produtoras possam competir por meio do lançamento de novos produtos no mercado.

\section{Conclusões e considerações finais}

A sustentabilidade requer mudanças significativas no sistema de produção industrial. É preciso "fazer mais com menos", pois a mitigação dos impactos ambientais dos processos de produção não é suficiente para alcançar-se esse objetivo. No caso dos refrigeradores, a remanufatura é uma alternativa relevante para a busca da sustentabilidade.

A observação dos resultados da ACV para o caso típico apresentado demonstra a escala significativa dos impactos ambientais que podem ser evitados com a adoção dessa estratégia. No entanto, mesmo com todas as 
possibilidades de ganhos econômicos para as empresas, apresentadas acima, e com a tendência de aprimoramento e evolução da legislação ambiental no Brasil, esta alternativa não se mostra viável para adoção em grande escala no cenário atual, em função, principalmente, das características dos produtos e do processo de fabricação, não projetados para a futura remanufatura dos refrigeradores.

Se houver a intenção de que esta indústria caminhe para essa solução (que, associada à implantação de rotinas de reciclagem de materiais, certamente contribuiria, em muito, para a construção da sustentabilidade), alguns caminhos de solução para as barreiras e dificuldades atuais podem ser apontados. Assim, a padronização de alguns modelos de refrigeradores, por exemplo, para que suas peças possam ser intercambiadas quando passarem pelo processo de remanufatura, a implantação, por meio de instrumentos legais e acordos entre os fabricantes, de contratos de longo prazo com fornecedores, para manter a operação do processo de remanufatura com suprimentos garantidos, e a introdução de inovações técnicas que permitam maior durabilidade e eficiência da espuma do isolamento térmico e do compressor são algumas vias de viabilização identificadas nesse trabalho. Nesse sentido, algumas alterações na legislação atual, para proporcionar incentivos à implantação da remanufatura, sistemática e em grande escala, de refrigeradores, são propostas a seguir.

A primeira proposta é a de fabricação de um modelo padrão de refrigerador que seja projetado com base nos conceitos de Projeto para Remanufatura. Nessas bases de projeto, quando o produto usado for descartado, haverá condições favoráveis à remanufatura, como a facilidade de desmontagem e de substituição das partes, peças ou componentes avariados, entre outras.

\section{Referências}

ABDI - Agência Brasileira de Desenvolvimento Industrial. Disponível em: <http://www.abdi.com.br/>. Acesso em: dezembro 2012.

ABNT - Associação Brasileira de Normas Técnicas. NBR 15833:2010. Manufatura Reversa-Aparelhos de refrigeração. Rio de Janeiro, 2010.
De acordo com a proposta, um certo percentual da produção da fábrica deve ser obrigatoriamente destinado à fabricação de um modelo padronizado, que poderia ser, por exemplo, o modelo de vendas mais expressivo. Um diferencial para esses modelos, que serviria para manter a possibilidade de renovação de padrões, seria a utilização de versões com cores diversas e com a utilização de módulos internos - como gavetas e prateleiras, de colocação variável, a ser decidida pelo comprador.

A segunda proposta seria a de incluírem-se os refrigeradores remanufaturados nas estratégias de compras do governo (para escolas, hospitais, creches, delegacias, etc.), para dar garantias de mercado e escala às empresas. $\mathrm{O}$ atual programa de substituição de refrigeradores obsoletos, por exemplo, também poderia ser incluído nessa proposta. Como o preço dos refrigeradores remanufaturados é inferior àqueles recém-fabricados, essa prática reduziria também os gastos com o orçamento público.

A terceira proposta seria a proposição de uma nova lei para oferecer estímulos econômicos às empresas produtoras de refrigeradores que incluírem o processo de remanufatura na rotina de suas práticas industriais, com a redução de impostos, financiamento a juros mais baixos e outros instrumentos afins.

Por fim, medidas como o apoio à formação das redes de fornecedores, a oferta de financiamento para os estudos técnicos que viabilizem a implantação da remanufatura, a difusão de informações para os consumidores e campanhas de incentivo à compra de aparelhos remanufaturados, com a menção às garantias a serem oferecidas aos compradores e aos preços mais baixos oferecidos, com a possibilidade de obtenção de desconto com a entrega do refrigerador usado ao fabricante no ato da compra do equipamento remanufaturado.

Anderi, Gil; Kulay, Luiz A. Avaliação do Ciclo de Vida. In: Vilela Júnior, A.; Demajorovic, J. Modelos e Ferramentas de Gestão Ambiental: desafios e perspectivas para as organizações. São Paulo: Editora Senac. São Paulo, 2006. p. 313-336.

Brasil. Presidência da República, Casa Civil. Lei 12.305, de 2 de agosto de 2010. Política Nacional de Resíduos Sólidos. 
2010a. Disponível em: <http://www.planalto.gov.br/ccivil_03/_Ato2007-2010/2010/Lei/L12305.htm>.

Presidência da República. Casa Civil. Decreto $n^{\circ}$ 7.404, de 23 de dezembro de 2010. 2010b. Disponível em: $<$ http://www.planalto.gov.br/ccivil_03/_Ato2007-2010/2010/ Decreto/D7404.htm>.

Cardoso, R. B. Avaliação da economia de energia atribuida ao Programa Selo PROCEL em freezers e refrigeradores. Itajubá, Minas Gerais, Dissertação (Mestrado em Engenharia da Energia) - Universidade Federal de Itajubá, 2008.

Chehebe, J. R. B. Análise do ciclo de vida de produtos: ISO 14000. Rio de Janeiro. Qualitymark Ed./CNI, 1997.

Chertow, M. R. Industrial symbiosis: literature and taxonomy. Annual Reviews Energy and Environment, 25, 313-337, 2000.

Eletrobras. Procel. Relatório Procel 2012. Rio de Janeiro, 2012.

ELETROS - Associação Nacional de Fabricantes de Produtos Eletroeletrônicos. Disponível em: <http://www.eletros.org.br>. Acesso em: março 2012.

Erkman, S. Industrial ecology: a historical view. Journal of Cleaner Production, 5(1-2), 1-10, 1997.

Industrial ecology: a new perspective on the future of the industrial system. Geneva: Institute for Communication and Analysis of Science and Technology (ICAST), 2001.

Fonseca, E. G. da. Economicamente incorreto. Guia Exame de Sustentabilidade, 2011.

Frosch. R.; Gallopoulos, N. Strategies for manufacturing. Scientific American, 261, 144-152, 1989.

Gehin, A.; Zwolinski, P.; Brissaud, D. A tool to implement sustainable end-of-life strategies in the product development phase. Journal of Cleaner Production, 16, 566-576, 2008.

Giannetti, B.; Almeida, C. Ecologia Industrial. Conceitos, ferramentas e aplicações. 1. ed. São Paulo: Edgar Blucher, 2006.

Giuntini, R.; Gaudette, K. Remanufacturing: The next great opportunity for boosting US productivity. Business Horizons, 2003.

Graedel, T. E.; Allenby, B. R. Industrial Ecology. Prentice Hall. AT\&T. 1995.

AT\&T, 1996.

. Design for Environment. Prentice Hall.

Gray, C.; Charter, M. Remanufacturing and product design. The Centre for Sustainable Design. Farnham, UK: University College for the Creative Arts, 2007.
Hatcher, G. D.; Ijomah, W. I.; Windmill, J. F. C. Design for remanufacture: a literature review and future research needs. Journal of Cleaner Production, 19, 2004-2014, 2011.

IBGE - Instituto Brasileiro de Geografia e Estatística. Pesquisa Nacional por Amostra de Domicílios - PNAD. 2011. Disponível em: <http://www.ibge.gov.br/home/estatistica/ populacao/trabalhoerendimento/pnad2011/default.shtm>. Acesso em: julho 2012.

Ijomah, W. L.; McMahon, C. M.; Hammond, G. P.; Newman, $\mathrm{S}$. T. Development of design for remanufacturing guidelines to support sustainable manufacturing. Robotics and Computer-Integrated Manufacturing, 23, 712-719, 2007.

INMETRO - Instituto Nacional de Metrologia, Qualidade e Tecnologia. Disponível em: $<$ http://www.inmetro.gov.br/consumidor/pbe/refrigeradores.pdf $>$. Acesso em: setembro 2012.

Jannuzzi, G. M. Análise de custo-beneficio de programa de substituição de refrigeradores domésticos para domicílios de baixa renda no Brasil. Agência dos Estados Unidos para o Desenvolvimento Internacional, 2007.

Junior, M. F.; Giannetti, B. F.; Almeida, C. M. V. B. Ecologia Industrial: projeto para meio ambiente. Revista de Graduação da Engenharia Química, ano VI, 12, jul.-dez. 2003.

Leite, Paulo Roberto. Logística reversa: meio ambiente e competitividade. São Paulo: Pearson Prentice Hall, 2009.

Lindahl, M.; Sundin, E.; Östlin, J. Environmental Issues within the Remanufacturing Industry. Department of Mechanical Engineering, Linköping University, Sweden. In: Proceedings of LCE 2006. Sweden, 2006.

Lopes, E.; Becker, D. Influência do uso do poliol reciclado obtido pela glicólise na preparação da espuma rígida de poliuretano. Polímeros, 22(2), 200-205, 2012.

Lund, R. Remanufacturing. Technology Review, 87, 1984.

; Hauser, W. Remanufacturing - An American perspective. ICRM 2010 - Green Manufacturing. China, 2010.

2012.

. The database of remanufacturers. Boston University.

Mähl, M.; Östlin, J. Lean Remanufacturing: Material Flows at Volvo Parts Flen. Uppsala: Department of Business Studies, Uppsala University, 2007.

MDIC - Ministério do Desenvolvimento, Indústria e Comércio Exterior. Disponível em: <http://www.desenvolvimento.gov. br/>. Acesso em: outubro 2012. 
ONU - Organização das Nações Unidas. Conferência sobre Desenvolvimento Sustentável $($ Rio +20$)$. O futuro que queremos. Rio de Janeiro, junho 2012.

Östlin, J. Material and Process complexity: Implications for Remanufacturing. Sweden: Linköping University, 2005.

. On Remanufacturing Systems: Analysing and Managing Material Flows and Remanufacturing Processes. Linköping Studies in Science and Technology, Thesis $\mathrm{N}^{\circ}$. 1192. Sweden: Linköping Universitet, 2008.

; Sundin, E.; Bjorkman, M. Product life-cycle implications for remanufacturing strategies. Journal of Cleaner Production, 17, 999-1009, 2009.

Parlamento Europeu. Diretiva 2002/96/CE, de 27 de janeiro de 2003. Jornal Oficial da União Europeia, 2003.

PNUMA - Programa das Nações Unidas para o Meio Ambiente. Disponível em: $<$ http://www.pnuma.org.br $>$. Acesso em: julho 2012.

Sachs, Ignacy. De volta à mão invisível: os desafios da segunda Cúpula da Terra no Rio de Janeiro. Estudos Avançados, 26, 2012.

Serra, E. G. Notas sobre capitalismo, meio ambiente e desenvolvimento. Novos Temas, 7, out. 2012.

Silva, G. A.; Kulay, L. A. Avaliação do ciclo de vida. Modelos e ferramentas de gestão ambiental: desafios e perspectivas para as organizações. Editora Senac, 2006. p. 313-336.
Sonnemann, G.; Castells, F.; Schuhmacher, M. Integrated life-cycle and risk assessment for industrial processes. Lewis Publisher, ACRC Press Company, 2003.

Sundin, E. Product and Process Design for Successful Remanufacturing. Department of Mechanical Engineering. Linköpings Universitet. Sweden. Dissertation No. 906, 2004.

.How can Remanufacturing Processes become Leaner? Sweden: Department of Mechanical Engineering. Linköping University. Linköping, 2006.

; Lee, H. M. In what way is remanufacturing good for the environment? In: Proceedings of Ecodesign 2011 International Symposium, 2011.

; Lindahl, M.; Ijomah, W. Product design for product/ service systems: Design experiences from Swedish industry. Journal of Manufacturing Technology Management, 20(5), 723-753, 2009.

UNEP - United Nations Environment Programme \& United Nations University. Sustainable Innovation and Technology Transfer Industrial Sector Studies. Recycling from e-waste to resources, 2009.

- United Nations Environment Programme. Montreal Protocol on Substances that Deplete the Ozone Layer. Report of The Refrigeration, Air Conditioning and Heat Pumps Technical Options Committee, 2010.

Worldwatch Institute. Estado do Mundo 2012. Disponível em: $<\mathrm{http}$ ://www.worldwatch.org.br/estado_2012.pdf $>$. Acesso em: junho 2012. 